\title{
Antinociceptive and Anti-inflammatory Effects of Combined Administration of a-tocopherol and Diclofenac
}

\author{
Tasneema Juaira' ${ }^{1}$, Noorzahan Begum², Taskina Ali ${ }^{3}$
}

\begin{abstract}
Background: Nonsteroidal anti-inflammatory drugs such as diclofenac are used for relief of pain and inflammation, but frequently cause gastrointestinal complications. This study aimed to explore that combination of diclofenac and $\alpha$-tocopherol $(\alpha \mathrm{T})$ are better analgesic as well as anti-inflammatory agent than that of diclofenac alone. Objective: To assess the effects of combination of diclofenac with $\alpha$-tocopherol on pain and inflammation. Methods: This prospective experimental study was conducted in the Department of Physiology, Bangabandhu Sheikh Mujib Medical University (BSMMU), Shahbag, Dhaka between January to December 2013. For this purpose, 15 male Long Evans rats were studied. On the basis of vitamin and drug administrations, the rats were divided into three (3) groups (5 rats in each). Control group received normal saline, one experimental group received diclofenac sodium (DS) at a dose of $10 \mathrm{mg} / \mathrm{kg} /$ body weight, and another experimental group received combination of DS with $\alpha \mathrm{T}$ at a dose of $10 \mathrm{mg} / \mathrm{kg} /$ body weight and $500 \mathrm{mg} / \mathrm{kg} /$ body weight, respectively. All the groups received single dose and equal volume $(1 \mathrm{ml})$ through intraperitoneal route 1 hour before the test. Just one hour after administrations, they were subjected to formalin test followed by formalin induced paw edema test. The data were statistically analyzed by ANOVA followed by Bonferroni Post Hoc test. Results: Combined administration of DS and $\alpha$ T significantly $(\mathrm{p} \leq 0.001)$ lowered the variables for nociceptive pain, central analgesic activity, inflammatory pain and inflammation than individual intervention of DS. Conclusion: From this study it may be concluded that, combined administration of diclofenac sodium and \pm -tocopherol were more effective in lowering pain and inflammation than individual administration of diclofenac.
\end{abstract}

Key words: Pain, analgesic, diclofenac, $\alpha$-tocopherol, formalin test, inflammation, paw edema.

J Bangladesh Soc Physiol. 2015, June; 10(1): 30-35 For Authors Affiliation, see end of text.

http://www.banglajol.info/index.php/JBSP

\section{Introduction}

$\mathbf{P}$ ain is an unpleasant sensation that is caused by actual or perceived injury to body tissues and produces physical and

emotional reactions. It is the most common symptom that causes people to seek out health care. Pain might be called a protector because, it protects and alerts us by triggering a reflexive

Received March 2015; $\quad$ Accepted May 2015 withdrawal from something damaging before we can suffer from further injury. Inflammation is also a complex biological response of vascular tissues to harmful stimuli such as pathogens, damaged cells or irritants ${ }^{1}$ It is part of the body's immune response. Initially, it is beneficial because, it promotes healing by removing the offending agent. However, sometimes inflammation can cause further inflammation. More inflammation 
is created in response to the existing inflammation.

Diclofenac sodium is an important non-steroidal anti-inflammatory drug widely used for human and animals to reduce pain as well as inflammation. Generally, it is used to treat pain associated with inflammatory disorders, dysmenorrhoea, mild to moderate post operative or post traumatic pain. It is often used to treat chronic pain associated with cancer ${ }^{2,3}$. However, long term use of diclofenac and similar nonsteroidal anti inflammatory drugs predispose to develop peptic ulcer and some other systemic manifestations ${ }^{3,4}$. Therefore, to minimize the use of these drugs, now a day's different animal studies have done to observe the effects of different vitamins on pain and inflammation with traditional analgesics ${ }^{5}$. Vitamin $\mathrm{E}$ is a fat soluble vitamin discovered by Evans and Bishop (1922) and $\alpha$-tocopherol $(\alpha \mathrm{T})$ is the most biologically active among its eight naturally available forms ${ }^{6-8}$. Many experimental studies have shown analgesic and anti-inflammatory effects of $\alpha \mathrm{T}$. Significant reduction of the nociceptive pain, inflammatory pain and inflammation was found after supplementation of this vitamin in different doses. Moreover, it has been reported that, $\alpha \mathrm{T}$ acts synergistically with NSAID's to reduce gastric inflammation and pain of peptic ulcer disease $^{9-12}$.

Now a day's administration of combination of analgesics with antioxidants in pain treatment are applied to decrease the doses of analgesics and to prevent the negative impact of reactive oxygen species ${ }^{17}$. But still the information's are not sufficient to reach any conclusion on this regard. Furthermore, in Bangladesh, no study has been conducted to observe the analgesic and anti-inflammatory effects of $\alpha$-tocopherol as well as its combination with diclofenac sodium as a single loading dose to compare their combined analgesic and anti- inflammatory effect with those of diclofenac alone.

\section{Methods}

This prospective experimental study was conducted in the Department of Physiology, Bangabandhu Sheikh Mujib Medical University (BSMMU), Shahbag, Dhaka from $1^{\text {st }}$ January to $31^{\text {st }}$ December 2013. Ethical permission was taken from the Institutional Review Board (IRB) of BSMMU, prior conducting the study.

Fifteeen male Long Evans rats, weighing 180 to 250 grams were collected from Bangladesh Institute of Research and Rehabilitation for Diabetic Endocrine and Metabolic Disorders (BIRDEM), Shahbag, Dhaka. They were kept under a 12/12 hour light/dark cycle ${ }^{18}$. The room temperature was kept at $28^{\circ} \mathrm{C} \pm 5^{0} \mathrm{C}$ which was corresponded to the thermo-neutral zone of rats ${ }^{19}$ at the Pain laboratory of the Department of Physiology, BSMMU. All the animals were acclimatized in the experimental laboratory environment for consecutive 7 days prior to the experiments and had free access to standard laboratory food and boiled water after cooling. All the experiments were performed during the day time between 8:00AM to 1:00 PM, to avoid the circadian influences. Experiments were conducted according to the guidelines for the Animal Experimentation Ethics Committee, Institute of Cholera and Diarrhoeal Disease Research, Bangladesh.

On the basis of vitamin and drug administrations, the rats were divided into 3 groups (5 rats/group). Control group received normal saline, diclofenac treated group received diclofenac sodium (DS) at a dose of $10 \mathrm{mg} / \mathrm{kg}$ body weight, and combination treated group received combination of DS with $\alpha$-tocopherol $(\alpha \mathrm{T})$ at a dose of $10 \mathrm{mg} /$ $\mathrm{kg} /$ body weight and $500 \mathrm{mg} / \mathrm{kg} /$ body weight, respectively. All the groups received single dose and equal volume $(1 \mathrm{ml})$ through intraperitoneal route 1 hour before the test. Just one hour after administrations, they were subjected to formalin test followed by formalin induced paw edema test. 
Formalin test:

On the day of experiment, the rat was adminstered by normal saline or DS or combined dose of DS and $\alpha \mathrm{T}$ intraperitonealy. One hour after adminstrations, the rat was restrained by a thick towel and the right hind paw was exposed. Fifty $\mu l$ of dilute formalin (2\%) was injected subcuteneously into the planter aspect of the right hind paw with an insulin syringe. Immediately the animal was placed in the observation cage of the plexiglas formalin box and the pain behaviors was observed for consecutive 60 minutes. Observation was made by counting the total frequency of jerking and total duration of flexing plus licking of the injected paw during this time through a mirror fixed below the formalin box at 45Ú angle. Within this time the first 5 minutes $\left(1^{\text {st }}-5^{\text {th }}\right)$ was considered as the early phase, middle 10 minutes $\left(6^{\text {th }}-15^{\text {th }}\right)$ as the interphase and last 45 minutes $\left(16^{\text {th }}-60^{\text {th }}\right)$ as the late phase. A stop watch was used to count the time.

Formalin induced paw edema test:

Just after completing the formalin test all the animals were sacrificed and both the hind paws were cut at their knee joints by a sharp scissor. Then the volume of both the paws were measured using a water plethysmometer ${ }^{18}$. Paw volume $=$ height of water column after paw immersion - height of water column before paw immersion . Net edema volume was calculated by substracing the left paw volume from the right paw volume.

All the data were expressed as mean \pm SE and statistical analysis was done by ANOVA followed by Bonferroni post hoc test. In the interpretation of results $\mathrm{p}$ value $<0.05$ was considered as significant.

\section{Results}

Antinociceptive effect

The effects of intraperitoneal (i.p) administration of DS and its combination with $\pm \mathrm{T}$ in early, inter and late phase were observed. In all the phases the pain behaviors were analyzed as total jerking frequency as well as total duration of flexing and licking.

In the early phase of formalin test, the mean values were significantly (pd”0.001) lowered in all the study groups than that of the controls. Moreover, the values in the combination treated group were lower in comparison to those of DS alone, though this difference was statistically significant $(\mathrm{p} \leq 0.001)$ only in duration of flexing and licking (Figure 1).
A

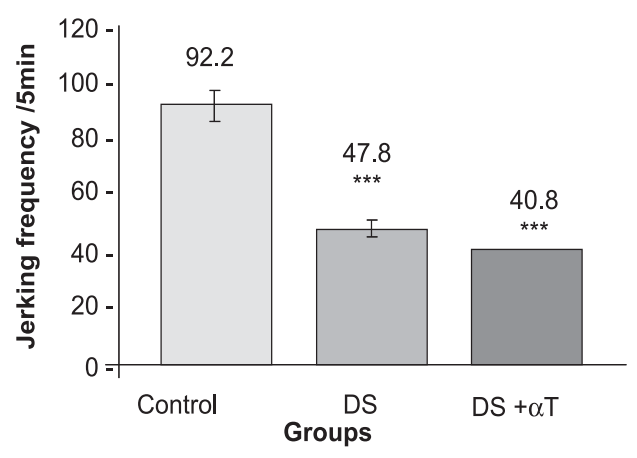

B

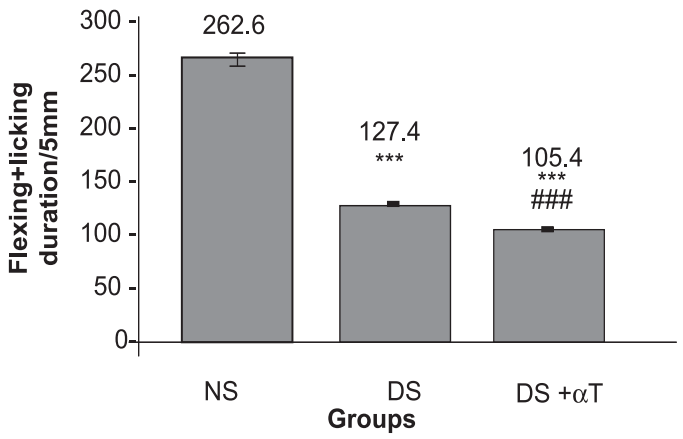

Figure 1: Frequency of jerking (A) and duration of flexing and licking (B) in early phase of formalin test in different groups of rats. Each bar symbolizes for mean \pm SE for 5 rats. $* * *=p<0.001$, compared to control and \#\#\# = p<0.001, comparison between DS vs DS $+\alpha \mathrm{T}$. 
Again, in the interphase, the mean values were significantly $(\mathrm{p} \leq 0.001)$ lower in all the study groups than that of the control groups. In addition, combined administration also reduced both the pain behaviors in comparison to administration of diclofenac alone, though it was statistically significant (pd”0.001) only in duration of flexing and licking (Figure 2).
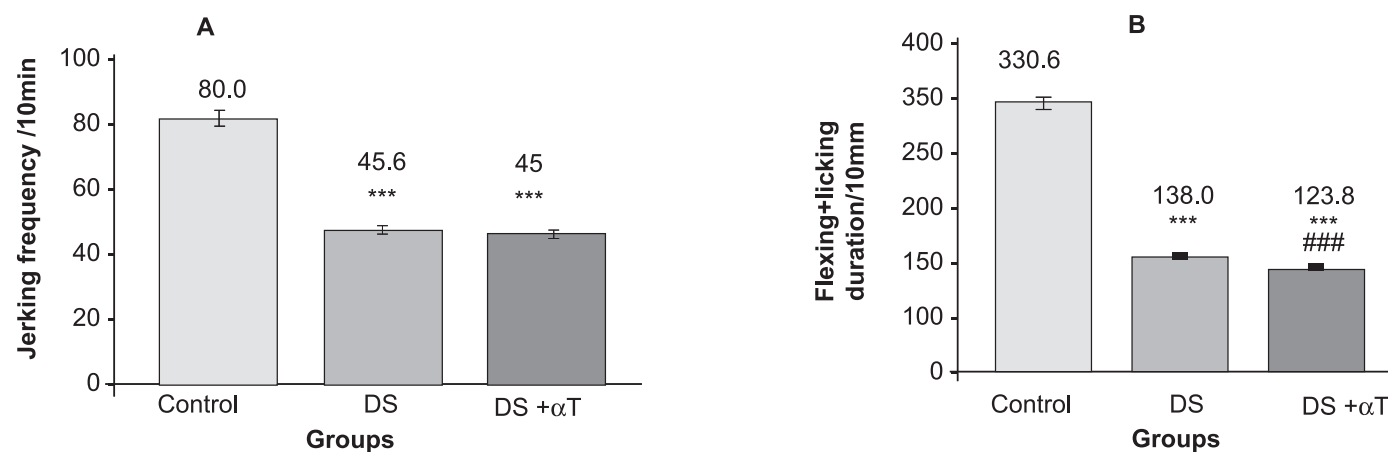

Figure 2: Frequency of jerking (A) and duration of flexing and licking (B) in interphase of formalin test in different groups of rats. Each bar symbolizes for mean $\pm S E$ for 5 rats. $* * *=p<0.001$, compared to control and \#\#\# = p<0.001, comparison between DS vs DS $+\alpha \mathrm{T}$.

Furthermore, in the late phase of formalin test, both the study groups showed reduction in both the pain variables significantly $(\mathrm{p} \leq 0.001)$ compared to control groups. In addition, combined administration significantly reduced the frequency of jerking (pd"0.05) and duration of flexing and licking (pd"0.001) than those of diclofenac alone (Figure 3).
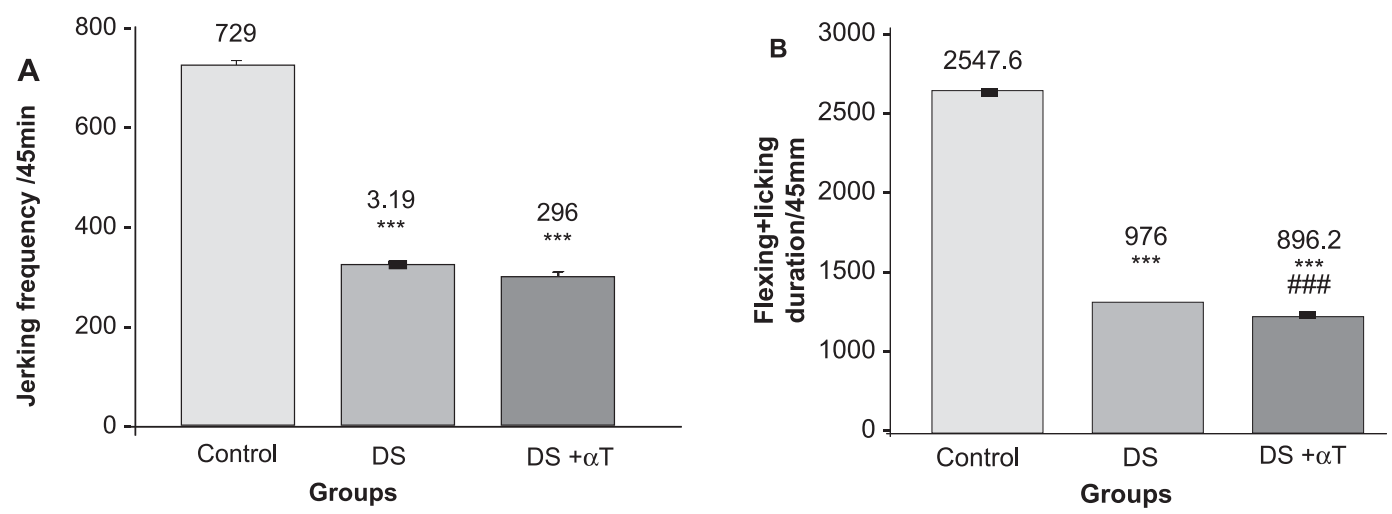

Figure 3: Frequency of jerking (A) and duration of flexing and licking (B) in late phase of formalin test in different groups of rats. Each bar symbolizes for mean \pm SE for 5 rats. $* * *=p<0.001$, compared to control; \# $=\mathrm{p}<0.05$ and \#\#\# = $<<0.001$, comparison between DS vs DS $+ \pm \mathrm{T}$.

Anti-inflammatory effect

The amount of edema in the formalin-injected paw was measured at the end of formalin test. All the mean values were significantly $(\mathrm{p} \leq 0.01)$ lowered in all the study groups than that of the controls. In addition, the paw edema was lowered more after combined administration in comparison to diclofenac alone but it was not statistically significant (Figure 4). 


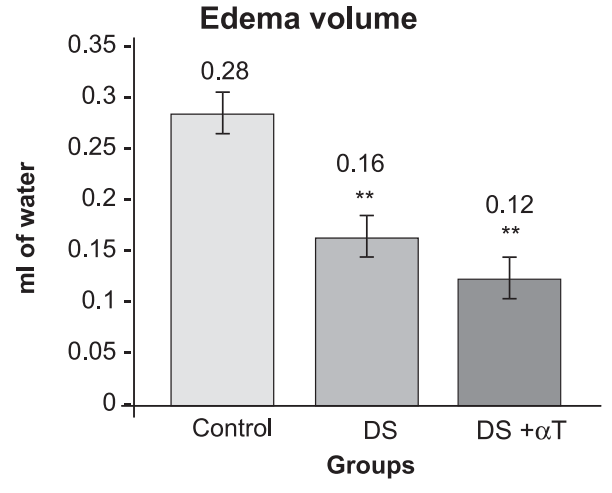

Figure 4: Formalin induced paw edema volume in different groups of rats. Each bar symbolizes for mean \pm SE for 5 rats. ${ }^{* *}=p<0.01$, compared to control.

\section{Discussion}

Management of pain and inflammation is considered as one of the major issues of healthcare systems worldwide. In addition to the body's own mechanism, there are a variety of approaches for treating them. With this view, the present study has been undertaken to assess the effects of combination of diclofenac sodium (DS) with $\alpha$-tocopherol $(\alpha \mathrm{T})$ on pain and inflammation.

The formalin test is a reliable method for the assessment of nociceptive pain, central mechanisms of nociception, and inflammatory pain in animal models and is sensitive for various classes of analgesic drugs ${ }^{13}$. This test shows an early phase, interphase and late phase. The early phase reflecting direct activation of nociceptors, the interphase shows the activation of central analgesic system and the late phase reflecting inflammation ${ }^{14}$. In our study, combined administration of drug and vitamin significantly lowered the nociceptive pain as well as the inflammatory pain and the enhanced central analgesic activity in comparison to that of diclofenac alone. Though the exact mechanisms of these effects could not be elucidated from this type of study, but several investigators suggested different mechanisms for the decrement of the nociceptive pain and enhancing central analgesic activity like increased activity of endogenous canabinoid or increment in the GABAergic or serotonergic neurons or ATP sensitive as well as voltage dependant $\mathrm{K}^{+}$ channels as the possible cause ${ }^{20,21}$.

In addition, among the different methods for measurement of inflammation in animals, formalin induced paw edema test is an accurate and simple method, where subcutaneous administration of formalin causes a local tissue injury ${ }^{15}$. This method is used for screening anti-inflammatory drugs also ${ }^{16}$. From the present study, the particular mechanism involved in significant lowering of inflammation (which have been observed in both the study groups) cannot be explained precisely. However some investigators suggested that lowering of inflammation and inflammatory pain might be due to inhibition of cyclooxygenase (COX), decrement of production of nitric oxide (NO), tumour necrosis factor (TNF$\alpha$ ), free radicals, prostaglandins or interleukin (IL6) 22,23 .

Along with these, in this study, combined administration of drug and vitamin have shown more effectiveness in lowering pain and inflammation than the drug alone, as evidenced by more decrement in all the study variables in the combined group. It is assumed that any the above mentioned mechanisms might be activated together and synergistically acted to cause more effectiveness in lowering different pain as well as inflammatory variables after administration of the combination of drug and vitamin.

\section{Conclusion}

From this study, it can be concluded that, combination of diclofenac and $\pm \mathrm{T}$ may be more effective in lowering pain and inflammation, than the individual administration of diclofenac. This data will apprise the clinicians and general populations to use $\alpha$-tocopherol along with diclofenac for better management of pain and inflammation.

\section{Conflict of interest : None}

J Bangladesh Soc Physiol. 2015, June; 10(1): 30-35 


\section{Author Affiliations}

1. *Tasneema Juaira, Assistant professor, Department of Physiology, Monno Medical College, Bangladesh. Email: sumontasneem@yahoo.com. Tel: +88-01718012137.

2. Noorzahan Begum,, Professor, Department of Physiology, Bangabandhu Sheikh Mujib Medical University ( BSMMU), Bangladesh. Email: noorzahan52@gmail.com

3. Taskina Ali, Associate Professor, Department of Physiology, Bangabandhu Sheikh Mujib Medical University ( BSMMU), Bangladesh. Email: taskinadr@gmail.com

*for correspondence

\section{References:}

1. Scott A, Khan KM, Cook JL, Duronio V. what is “inflammation"? Are we ready to move beyond Celsus? Br J Sports Med 2004;38: 248-49.

2. Fini A, Garuti M, Fazio G, Alvarez-Fuentes J, Holgado MA. Diclofenac salts. I. Fractal and thermal analysis of sodium and potassium diclofenac salts. J Pharm Sci 2001; 90(12): 2049-57.

3. Brunton LL, Lazo JS, Parker KL. Goodman and Gilmans-The pharmacological Basis of Therapeutics. $11^{\text {th }}$ ed, McGraw-Hill medical publishing division; 2011. 973-987p.

4. Rainsford KD, Kean WF, Ehrlich GE. Review of the pharmaceutical properties and clinical effects of the topical NSAID formulation, diclofenac epolamine. Curr med res opn 2008;24(10):.

5. Majagi SI, Bhosle TN, Patil PA. Anti inflammatory and analgesic activity of $\mathrm{D}_{1}$ Alpha-tocopheryl Acetate and its interaction with aspirin in Wister rats. IJDDR 2011; 3(4):86-93.

6. Edmonds SE, Winyard PG, Guo R, Kidd B, Merry P, Smith AL, Hansen C, Ramm S, Blake DR. Putative analgesic activity of repeated oral doses of vitamin $\mathrm{E}$ in the treatment of rheumatoid arthritis. Results of a prospective placebo controlled double blind trial. Ann Rheum Dis 1997; 56: 649-55.

7. Azzi A, Stocker A. Vitamin E: non-antioxidant roles. 2000; 39: 231-255.

8. Kaya NE. Alpha-tocopherol: looking beyond an antioxidant. Molecular vision. 2009;15: 855-860.

9. Lazzarini M, Salum C, Del Bel EA. Combined treatment of ascorbic acid or alpha-tocopherol with receptor antagonist or nitric oxide synthase inhibitor potientiates cataleptic effect in mice. Psychopharm 2005;181: 71-79.
10. Lu R, Gerhardt WK, Geisslinger G, Schmidtko A. Additive antinociceptive effects of a combination of vitamin $\mathrm{C}$ and vitamin $\mathrm{E}$ after peripheral nerve injury. Plos one 2011; 6(12).

11. Kim MJ, Boo HH, En JZ, Young KK, Won HL. Anti nociceptive effects of intraperitoneal and intrathecal vitamin $\mathrm{E}$ in the rat formalin test. Korean J Pain. 2012; 25(4): 238-244.

12. Tiwari V, Kuhad A, Chopra K. Neuroprotective Effect of Vitamin E isoforms against chronic alcohol-induced peripheral neurotoxicity: possible involvment of oxidative nitrodative stress. Phytother. Res. 2012 wileyonlinelibrary. Com.

13. Dubuisson D, Dennis SG. The formalin test: a quantitative study of the analgesic effects of morphine, meperidine and brain stem stimulation in rats and cats. Pain 1977;4(2): 161-74.

14. Henry JL, Yashpal K, Pitcher GM, Coderre TJ. Physiological evidence that the 'interphase' in the formalin test is due to active inhibition. Pain.1999;82(1): 57-63.

15. Ferreidoni M, Ahmadiani A, Semnanian S, Javan M. An accurate and simple method for measurement of paw edema. J Pharmacol Toxicol Methods. 2000; 43:11-14.

16. Vogel HG, Vogel WH, Scholkens BA, Sandow J, Muller G, Vogel WF. Drug discovery and evaluation pharmacological assay. $2^{\text {nd }}$ ed. Berlin: Springer. 2002 . p 669-774.

17. Rokyta R, Václav H, Ivana P, Jana K, Jaroslav R, Ladislav T, Anna Y. Free radicals after painful stimulation are inûuenced by antioxidants and analgesics. Neuroendocrinol Lett 2003;24(5): 304-309.

18. Tajik H, Esmaeal T, Nasrin H. Effect of curcumin on the acetic acid- induced visceral nociception in rats. Pakistan J Biol sci 2008; 11(2): 312-314.

19. Uddin Z, Aninda KN, Anowara J, Mycal D, Masud MM, Talha BE. Analgesic activities of Crinum asiaticum . Mol and clin pharmacol 2012; 3(2): 125-33.

20. Bardin L. The complex role of serotonin and 5HT receptors in chronic pain. Behav Pharmacol. 2011;22(56): 390-404

21. Nadine C, Ferreira MC, Solal CC, Kadmi CM, Bernad N, Martinez J, Barbanel G, Vignes M, Guiramand J. \pm -tocopheryl phosphate interact with the cannabinoid system in the rodent hippocampus. Free Radic Biol Med 2011;51: 1643-55.

22. Alorainy M. Effect of allopurinol \& vitamin E on rat model of rheumatoid arthritis. Int $\mathrm{J}$ health Sci. 2008;2(1): 59-67.

23. Hasani A, Marjia S, Muharrem J, Serpil U. Preemptive analgesic effect of midazolam and diclofenac in rat model. Bosnian J Basic Med. Sci 2011;2:113-1.y 